\title{
Estimation of Median Lethal Dose of Fenpropathrin in Wistar Rat
}

\author{
Nisha Manglani ${ }^{*}$, Diksha Bhatt ${ }^{2}$, Shakuntala Singh ${ }^{1}$, P. J. John' and Inderpal Soni' \\ 'Environmental Toxicology Laboratory, Department of Zoology, University of Rajasthan, Jaipur - 302004, \\ Rajasthan, India; nisha.manglani8524@gmail.com, inderpalsoni@gmail.com \\ ${ }^{2}$ Assistant Professor and Head, Government Nehru PG College, Ashoknagar,Madhya Pradesh - 473331, India; \\ bhatt.diksha@gmail.com
}

\begin{abstract}
Background: Fenpropathrin, a synthetic pyrethroid (Type I/II) is commonly used as an insecticide in homes and in agriculture. The present study was planned to determine the median lethal dose $\left(\mathrm{LD}_{50}\right)$ of Fenpropathrin in adult Wistar rats, both male and female. Statistically, $\mathrm{LD}_{50}$ is a first screening step to asses and evaluate the toxicity for a chemical that causes death of $50 \%$ population of test animals when given by a specified route as a single dose for a specific time period. Methods: The experimental rats were divided into 10 groups ( 5 of male and 5 of female rats) and ten rats were divided into each group. For each group of animals, a single oral dose of Fenpropathrin dissolved in corn oil was administered orally at 15, 30, 45, 60 and $75 \mathrm{mg} / \mathrm{kg}$ body weight (bw) concentrations. The animals were monitored up to 96 hours to assess the signs of toxicity and to calculate the $\mathrm{LD}_{50}$ as per the graphical method procedure suggested by Miller and Tainter $(1944)^{10}$. Result: Estimated $\mathrm{LD}_{50}$ of Fenpropathrin was found to be $52.72 \pm 8.61 \mathrm{mg} / \mathrm{kg}$ body weight in male rats and $48.08 \pm 8.13 \mathrm{mg} / \mathrm{kg}$ body weight in female rats. There were no toxic signs or behavioural changes in the single oral dose of Fenpropathrin at $10 \mathrm{mg} / \mathrm{kg}$ body weight, thus it can be considered as No Observed Adverse Effect Level (NOAEL). Conclusion: It can beconcluded from the study that Fenpropathrin is highly toxic pyrethroid due to its low $\mathrm{LD}_{50}$ value in Wistar rats.The result of this study may serve as a basis for dose administration for further research on Fenpropathrin toxicity.
\end{abstract}

Keywords: Fenpropathrin, Pyrethroid, Lethal Dose $\left(\mathrm{LD}_{50}\right)$, Wistar Rat

\section{Introduction}

Pyrethroids are natural known toxins produced by flowers of pyrethrum (Chrysanthemum cinerariaefolium and $C$. coccineum) and are currently the most extensively used class of pesticides. Usage of pyrethroids as insecticides has increased in recent years for agriculture and domestic applications resulting in greater exposure of human beings, as a result many questions arise concerning their adverse side effects and action mechanism in non-target species ${ }^{1}$. Based on the chemical structure and toxicity signs, pyrethroids fall into 2 distinct groups: Type I and Type $\mathrm{II}^{2-4}$. Those that lack cyano group on the phenoxybenzyl moiety are Type I pyrethroids and they are characterized by the T-syndrome (tremors) affecting sodium channels in nerve membranes and cause vigorous sparring, high responsiveness external stimuli, fine tremors progressing to entire body tremors and prostration. Type II pyrethroidsin the alcohol moiety have an alpha-cyano group and produce a longer delay in inactivation of sodium channel ${ }^{4,5}$. These are characterized by CS syndrome (choreoathetosis and salivation). A few pyrethroids can inducetremors and also salivation and were graded as accordingly Type I/II pyrethroids ${ }^{2,4}$.

Fenpropathrin [(RS) a-cyano-3-phenoxybenzyl 2,2,3,3 -tetramethylcyclopropanecarboxylate] is a highly toxic synthetic pyrethroid insecticide which is included in Type I/II pyrethroid as it causes tremors as well as salivation in animal models ${ }^{6}$. Commonly, it is used to control a wide range of insect pests to enhance the production of crops. Fenpropathrin acts on the nervous system of insects, and disturbs the function of neurons as it binds to $\mathrm{NaV}$ (voltagesensitive sodium) channels and modifies their gating kinetics. Being lipophilic in nature, Fenpropathrin crosses the blood brain barrier andhas been found to accumulate in brain and induce neurotoxicity ${ }^{7}$. Therefore, misapplication

*Author for correspondence 
or accidental exposure to Fenpropathrin may cause severe toxic effects on human beings and non-target organism.

To find out the Acceptable Daily Intake (ADI) and other adverse effects of Fenpropathrin, we need to perform toxicity test. To assess potential hazards to humans, acute, sub-chronic and chronic toxicity tests are conducted on laboratory animals.

Acute toxicity tests evaluate toxic effects when a chemical substance is absorbed from a single or multiple exposures into the body, through mouth, skin or lungs over a short period of time (usually within 24 hours). It is one of the most common way to quantify a chemical substance's potential to trigger ill effects "relatively soon". Median lethal dose $\left(\mathrm{LD}_{50}\right)$ figures of a substance's acute toxicity measured by any accepted method such as given by Bliss $(1934)^{9}$, Miller and Tainter $(1944)^{10}$, Litchfield and Wilcoxon (1949) ${ }^{11}$, Thompson $(1947)^{12}$, Weil (1952) $)^{13}$ and Finney $(1971)^{14}$ under controlled and standardized laboratory conditions. This information can be used to deal with cases of accidental ingestion of material and provides data in sub-chronic and chronic studies to create a dosage regimen. Generally, toxicity tests are conducted in rats and other animal models and are used to set standards for human toxicity.

Commonly, acute toxicity expressed as $\mathrm{LD}_{50}$, where $\mathrm{LD}$ means a lethal dose and subscript 50 means that the dose is acutely lethal to $50 \%$ of the animals. Therefore, this evaluates the relation between the dosage and the severe response i.e. death. The chemical is highly toxic when its $\mathrm{LD}_{50}$ value is low. An attempt was madehere to determine Fenpropathrin's oral $\mathrm{LD}_{50}$ (corn oil as a vehicle) in Wistar rats.

\section{Materials and Methods}

\subsection{Experiment Chemical}

Fenpropathrin PESTANAL ${ }^{\circ}$, analytical standard (CAS No. 39515-41-8) was purchased with $99.8 \%$ purity from SigmaAldrich, Germany.

\subsection{Procurement of Animals and Ethics Approval}

Adult Wistar rats (male and female) were randomly selected for present study. They were kept in an air-cooled room at $25 \pm 3{ }^{\circ} \mathrm{C}$ with a light and dark cycle (12-12 h) under regular laboratory conditions. Prior to the initiation of the experiment, they were acclimatized to the basal diet for three days. Throughout the experiment, Animals were maintained on regular pellet diet purchased from Ashirwad Industries, Chandigarh, India and water ad libitum. The investigational procedure was approved by DAEC(Departmental Animal Ethical Committee) and animal care committee, and handling was conforms to the guidelines set by CPCSEA(Committee for the Purpose of Control and Supervision of Experiments on Animals), New Delhi, India.

\subsection{Dose Preparation and Administration}

Adult Wistar rats aged sixty days and weighing $150 \pm 5 \mathrm{~g}$ were chosen for the experiment. Prior to dosing, animals were fasted for eighteen hours because feeding tends to increase the metabolic activities such as rates of respiration, excretion or production of other waste products, which affect the toxicity. In the present study, the doses of Fenpropathrin dissolved in $0.5 \mathrm{ml}$ of corn oil and administered once orally to the rats as a single doseby intubation cannula.

\subsection{Approximation of Dose Range and Mortality Percentage}

Initially, Approximate $\mathrm{LD}_{50}$ was calculated by a pilot study named "up and down" using two animals with gradually increasing doses of Fenpropathrin. Six doses were picked viz. $5,10,20,40,80$ and $160 \mathrm{mg} / \mathrm{kgbw}$ for determination of approximate $\mathrm{LD}_{50^{\circ}}$. The results of this pilot study indicated approximate $\mathrm{LD}_{50}^{50}$ for male and female rats at $50 \mathrm{mg} / \mathrm{kgbw}$ and $40 \mathrm{mg} / \mathrm{kg}$ bw respectively. Fenpropathrin did not produce any toxic effects at $5 \mathrm{mg} / \mathrm{kg}$ bw and $10 \mathrm{mg} / \mathrm{kg}$ bw dose levels, hence $10 \mathrm{mg} / \mathrm{kg}$ may be considered as NOAEL (No Observed Adverse Effect Level). Doses from $20 \mathrm{mg} / \mathrm{kg}$ bw to $160 \mathrm{mg} / \mathrm{kg}$ bw showed signs of toxicity viz. salivation, choreoathetosis, seizures, aggressive sparring, whole body tremors and prostration in the treated animals of both sexes.

We conducted confirmatory experiments in accordance with the method provided by Miller and Tainter (1944), based on the results of our pilot study ${ }^{10}$. Total 10 groups (5 groups of male and 5 groups of female rats) were selected, each containing 10 animals. For both the sexes, 5 doses of Fenpropathrin viz. 15, 30, 45, 60 and $75 \mathrm{mg} / \mathrm{kg}$ bw were chosen. Simultaneously two groups (one of male and one of female) of control animals were received $0.5 \mathrm{ml}$ of corn oil through the same route of administration. Mortality was then calculated from $0 \%$ to $100 \%{ }^{15}$. Forthe toxic signs and symptoms the rats were observed for 2 hours and then for 4 , 6, 24, 48, 72 and 96 hours. Any change in behaviour pattern and other responses were carefully noted. After 96 hours, the number of deceased rats in every single group was counted. The mortality \% was estimated as per the graphical method procedure proposed by Miller and Tainter $(1944)^{10}$.

\section{Results}

\subsection{Toxicity Symptoms}

Initially, Fenpropathrin did not produce any significant effect on central nervous system (CNS) up to $10 \mathrm{mg} / \mathrm{kg}$ bw dose level. However, when the doses of $20 \mathrm{mg} / \mathrm{kg}$ bw to $160 \mathrm{mg} /$ $\mathrm{kg}$ bw were administered, the animals of both sexes showed 
signs of toxicity viz. salivation, choreoathetosis, seizures, aggressive sparring, whole body tremors and prostration. The animals exhibited writhing and twisting movement of the neck and tail due to choreoathetosis, followed by laboured breathing, gasping, and death. The parameters observed for toxicity study after the administration of the Fenpropathrin in selected doses groups compared with control groups are presented in Table 1.

Table 1. Observations of overall health and behaviour in control and treated groups

\begin{tabular}{|c|c|c|c|c|c|c|c|}
\hline Observation & Sex & Control group & $15 \mathrm{mg} / \mathrm{kg}$ bw & $30 \mathrm{mg} / \mathrm{kg} \mathrm{bw}$ & $45 \mathrm{mg} / \mathrm{kg} \mathrm{bw}$ & $60 \mathrm{mg} / \mathrm{kg}$ bw & $75 \mathrm{mg} / \mathrm{kg}$ bw \\
\hline \multirow{2}{*}{ Body weight } & M & (:) & $\odot$ & $\odot$ & $\odot$ & $\odot$ & $\odot$ \\
\hline & $\mathrm{F}$ & (:) & $\odot$ & $\odot$ & $\odot$ & () & $\odot$ \\
\hline \multirow{2}{*}{ Temperature } & M & (-) & (-) & (-) & $\bullet$ & $\boldsymbol{\Delta}$ & $\boldsymbol{\Delta}$ \\
\hline & $\mathrm{F}$ & ;) & ;) & $\bullet$ & $\bullet$ & $\boldsymbol{\Delta}$ & $\Delta$ \\
\hline \multirow{2}{*}{ Salivation } & M & () & () & $\Delta$ & $\boldsymbol{\Delta}$ & $\boldsymbol{\Delta}$ & $\boldsymbol{\Delta}$ \\
\hline & $\mathrm{F}$ & $\odot$ & () & $\boldsymbol{\Delta}$ & $\boldsymbol{\Delta}$ & $\boldsymbol{\Delta}$ & $\boldsymbol{\Delta}$ \\
\hline \multirow{2}{*}{ Lethargy } & M & - & - & - & + & + & + \\
\hline & $\mathrm{F}$ & - & - & + & + & + & + \\
\hline \multirow{2}{*}{ Tremors } & M & - & - & - & + & + & + \\
\hline & $\mathrm{F}$ & - & - & - & + & + & + \\
\hline \multirow{2}{*}{ Seizures } & M & . & - & + & + & + & + \\
\hline & $\mathrm{F}$ & . & - & + & + & + & + \\
\hline \multirow{2}{*}{ Choreoathetosis } & M & - & + & + & + & + & + \\
\hline & $\mathrm{F}$ & - & + & + & + & + & + \\
\hline \multirow{2}{*}{ Drowsiness } & M & - & - & + & + & + & + \\
\hline & $\mathrm{F}$ & - & + & - & + & + & + \\
\hline \multirow{2}{*}{ Sedation } & M & $\odot$ & $\odot$ & $\odot$ & - & - & - \\
\hline & $\mathrm{F}$ & $\odot$ & ๑) & घ & घ & घ & घ \\
\hline \multirow{2}{*}{ Blinking of eyes } & M & (:) & (:) & $\bullet$ & $\Delta$ & $\Delta$ & $\Delta$ \\
\hline & $\mathrm{F}$ & (-) & $\bullet$ & $\Delta$ & $\Delta$ & $\Delta$ & $\Delta$ \\
\hline \multirow{2}{*}{ Scratching } & M & - & - & + & + & + & + \\
\hline & $\mathrm{F}$ & - & + & + & + & + & + \\
\hline \multirow{2}{*}{ Aggression } & M & - & - & $\Delta \boldsymbol{\Delta}$ & $\Delta \boldsymbol{\Delta} \boldsymbol{\Delta}$ & $\Delta \mathbf{\Delta} \Delta$ & $\Delta \boldsymbol{\Delta} \Delta$ \\
\hline & $\mathrm{F}$ & - & - & $\bullet$ & $\Delta \boldsymbol{\Delta} \boldsymbol{\Delta}$ & $\boldsymbol{\Delta} \boldsymbol{\Delta} \boldsymbol{\Delta}$ & $\boldsymbol{\Delta} \boldsymbol{\Delta} \boldsymbol{\Delta}$ \\
\hline \multirow{2}{*}{ Excitation } & M & (2) & + & + & + & + & + \\
\hline & $\mathrm{F}$ & (); & + & + & + & + & + \\
\hline \multirow{2}{*}{ Thirst } & M & (:) & $\Delta$ & $\Delta$ & $\Delta$ & $\Delta$ & $\Delta$ \\
\hline & $\mathrm{F}$ & (-) & $\Delta$ & $\Delta$ & $\Delta$ & $\Delta$ & $\Delta$ \\
\hline \multirow{2}{*}{ Food intake } & M & (-) & (-) & $\nabla$ & $\nabla$ & $\nabla$ & $\nabla$ \\
\hline & $\mathrm{F}$ & (-) & $\nabla$ & $\nabla$ & $\nabla$ & $\nabla$ & $\nabla$ \\
\hline \multirow{2}{*}{ Urination } & M & :) & (:) & $\square$ & $\square$ & $\square$ & $\square$ \\
\hline & $\mathrm{F}$ & (); & $\square$ & $\square$ & $\square$ & $\square$ & $\square$ \\
\hline \multirow{2}{*}{ Rate of respiration } & $\mathrm{M}$ & (:) & $\odot$ & $\mathbf{\Delta}(\mathbf{L B})$ & $\mathbf{A}(\mathbf{L B}, \mathbf{g})$ & $\mathbf{\Delta}(\mathbf{L B}, \mathbf{g})$ & $\mathbf{\Delta}(\mathbf{L B}, \mathbf{g})$ \\
\hline & $\mathrm{F}$ & (2) & $\mathbf{A}(\mathbf{L B})$ & $\mathbf{A}(\mathbf{L B})$ & $\Delta(\mathbf{L B}, \mathbf{g})$ & $\mathbf{\Delta}(\mathbf{L B}, \mathbf{g})$ & $\mathbf{\Delta}(\mathbf{L B}, \mathbf{g})$ \\
\hline \multirow{2}{*}{ Mortality } & $\mathrm{M}$ & $0 \%$ (Alive) & $0 \%$ & $10 \%$ & $40 \%$ & $60 \%$ & $80 \%$ \\
\hline & $\mathrm{F}$ & $0 \%$ (Alive) & $0 \%$ & $20 \%$ & $50 \%$ & $70 \%$ & $90 \%$ \\
\hline
\end{tabular}

Abbreviations/signs: (M), male; (F), female; ( $\odot)$, Normal; ( $\bullet$ ), No effect; (-), Not present; (+), Present; ( $\mathbf{\Delta}$ ), Increased; (४), Slightly increased; ( $\boldsymbol{\Delta} \mathbf{\Delta}$ ), Moderately Increased; ( $\mathbf{\Delta} \boldsymbol{\Delta} \mathbf{\Delta}$ ), Highly Increased; ( $\mathbf{})$, Observed; ( $\square$ ), Frequent; (LB), Laboured breathing; (g), gasping $(\boldsymbol{\nabla})$, Decreased. 


\subsection{Transformation of \%Mortalities to Probits and Calculation of $\mathrm{LD}_{50}$}

At each Fenpropathrin dose level, the number of deceased male and female rats was recorded (Tables 2 and 3). By
Finney's method, the \% (percentage) of animals that died at each dose level was converted to probit (Table 4$)^{14}$.

In the present study, for male rats $\log \mathrm{LD}_{50}$ is 1.722 (Figure 1) and calculated $\mathrm{LD}_{50}$ is $52.72 \mathrm{mg} / \mathrm{kg}$ bw and for the female rats $\log \mathrm{LD}_{50}$ is 1.682 (Figure 2) and $\mathrm{LD}_{50}$ is $48.08 \mathrm{mg} / \mathrm{kg} \mathrm{bw}$ were obtained.

Table 3. Results of Fenpropathrin lethal doses for $\mathrm{LD}_{50}$ calculation in female Wistar rats

\begin{tabular}{|c|c|c|c|c|}
\hline Group & $\begin{array}{c}\text { Dose (mg/ } \\
\mathbf{k g} \text { bw) }\end{array}$ & Log Dose & \% Dead & Probits \\
\hline $\mathbf{1}$ & 15 & 1.176 & 0 & 0 \\
\hline $\mathbf{2}$ & 30 & 1.477 & 20 & 4.16 \\
\hline $\mathbf{3}$ & 45 & 1.653 & 50 & 5.00 \\
\hline $\mathbf{4}$ & 60 & 1.778 & 70 & 5.52 \\
\hline $\mathbf{5}$ & 75 & 1.875 & 90 & 6.28 \\
\hline
\end{tabular}

Table 4. Conversion of \% mortalities to probit

\begin{tabular}{|c|c|c|c|c|c|c|c|c|c|c|}
\hline $\mathbf{0}$ & $\mathbf{0}$ & $\mathbf{1}$ & $\mathbf{2}$ & $\mathbf{3}$ & $\mathbf{4}$ & $\mathbf{5}$ & $\mathbf{6}$ & $\mathbf{7}$ & $\mathbf{8}$ & $\mathbf{9}$ \\
\hline $\mathbf{0}$ & - & 2.67 & 2.95 & 3.12 & 3.25 & 3.36 & 3.45 & 3.52 & 3.59 & 3.66 \\
\hline $\mathbf{1 0}$ & 3.72 & 3.77 & 3.82 & 3.87 & 3.92 & 3.96 & 4.01 & 4.05 & 4.08 & 4.12 \\
\hline $\mathbf{2 0}$ & 4.16 & 4.19 & 4.23 & 4.26 & 4.29 & 4.33 & 4.36 & 4.39 & 4.42 & 4.45 \\
\hline $\mathbf{3 0}$ & 4.48 & 4.50 & 4.53 & 4.56 & 4.59 & 4.61 & 4.64 & 4.67 & 4.69 & 4.72 \\
\hline $\mathbf{4 0}$ & 4.75 & 4.77 & 4.80 & 4.82 & 4.85 & 4.87 & 4.90 & 4.92 & 4.95 & 4.97 \\
\hline $\mathbf{5 0}$ & 5.00 & 5.03 & 5.05 & 5.08 & 5.10 & 5.13 & 5.15 & 5.18 & 5.20 & 5.23 \\
\hline $\mathbf{6 0}$ & 5.25 & 5.28 & 5.31 & 5.33 & 5.36 & 5.39 & 5.41 & 5.44 & 5.47 & 5.50 \\
\hline $\mathbf{7 0}$ & 5.52 & 5.55 & 5.58 & 5.61 & 5.64 & 5.67 & 5.71 & 5.74 & 5.77 & 5.81 \\
\hline $\mathbf{8 0}$ & 5.84 & 5.88 & 5.92 & 5.95 & 5.99 & 6.04 & 6.08 & 6.13 & 6.18 & 6.23 \\
\hline $\mathbf{9 0}$ & 6.28 & 6.34 & 6.41 & 6.48 & 6.55 & 6.64 & 6.75 & 6.88 & 7.05 & 7.33 \\
\hline
\end{tabular}

\subsection{Standard ErrorCalculation of $\mathrm{LD}_{50}$}

With the following formula given by Ghosh $(1984)^{16}$, SE of the $\mathrm{LD}_{50}$ was determined. $(\mathrm{N}=$ Number of animals in each group)

Approximate Standard Error of $\mathbf{L D}_{50}=\left(\log \mathbf{L D}_{84}-\log \mathbf{L D}_{16}\right) \sqrt{2} \mathrm{~N}$

The Probits of 84 and 16 are calculated from Table (4) and found to be 5.99 and 4.01 (approximately 6 and 4), respectively. In case of male rats, the log LD values for the probits 6 and 4 are 1.844 and 1.602 (obtained from the line on the graph in Figure 1) and their antilogs are 69.82 and 39.99 respectively. In case of female rats, the log LD values for the probits 6 and 4 are 1.801 and 1.561 (obtained from the line on the graph in Figure 2) and their antilogs are 64.56 and 36.39 respectively. After putting these values in formula (1), the Standard Error of $\mathrm{LD}_{50}$ is 8.61 for male rat and 8.13 for female rat. Therefore, $\mathrm{LD}_{50}$ Fenpropathrin in corn oil for male rat is $52.72 \pm 8.61$ and $48.08 \pm 8.13$ when given orally, with $95 \%$ confidence interval. 


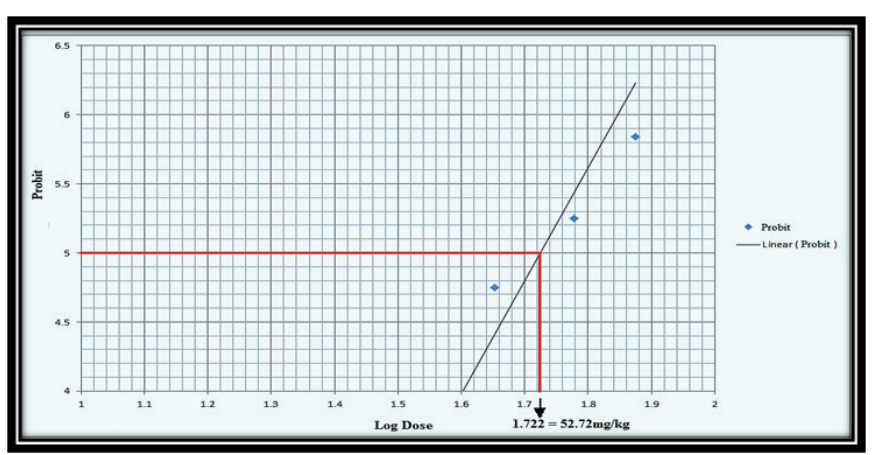

Figure 1. Graph plot showing Log doses probit from Table 4 for the calculation of oral $\mathrm{LD}_{50}$ of Fenpropathrin in male Wistar rats.

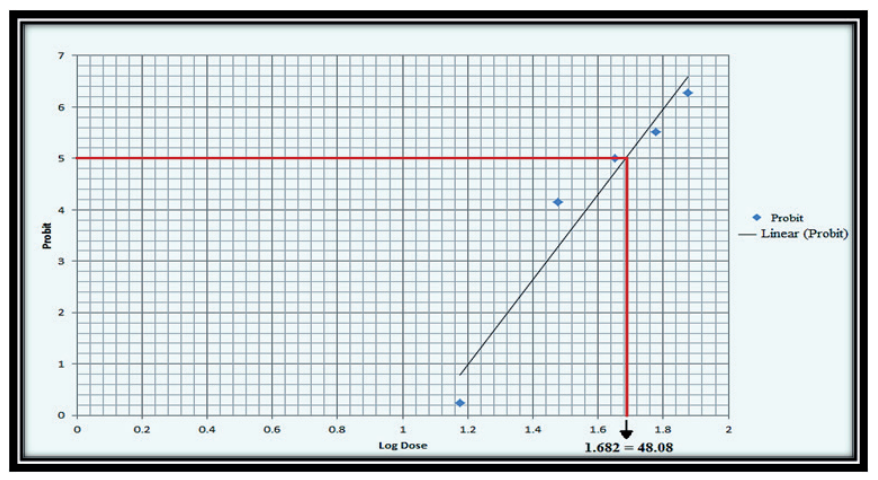

Figure 2. Graph plot showing Log doses versus probit from Table 4 for the calculation of oral $\mathrm{LD}_{50}$ of Fenpropathrin in female Wistar rats.

\section{Discussion}

Synthetic pyrethroids are available in wide variety of insecticide formulations and extensively used in indoor and outdoor environments, including agriculture, horticulture, public health initiatives and veterinary use for pest control because of their high bio-efficacy ${ }^{17}$. In recent years, excessive production and application of pyrethroid pesticides has raised potential environmental hazards to animals and humans as they accumulate in the food chain ${ }^{18}$. Biological testing and monitoring assessed the presence of pesticide residues in fresh or cooked fruits and vegetables and in processed food products ${ }^{19}$. Consumption of these food products has been linked to high levels of exposure to pesticide. Epidemiological evidence, medical reports and research laboratory studies suggest that pyrethroid exposure contributes to immunotoxic, neurotoxic, reproductive toxicity effects, developmental defects and behavioural disorders in humans and animals, despite being considered reasonably safe for humans ${ }^{20-26}$. Thus, it becomes important to know the $\mathrm{LD}_{50}$ of the pyrethroidpesticides before using them.
The current research was conducted to investigate, the Fenpropathrin's acute oral toxicity in both sexes of Wistar rats. The pesticide dissolved in corn oil and administered once orally to rats at different dose levels $(15,30,45,60$ and $75 \mathrm{mg} / \mathrm{kg} \mathrm{bw}$ ) as recommended in OECD/OCED Guidelines $(2001)^{27}$. The male and female experimental rats exhibited common symptoms of pyrethroid toxicity i.e. salivation, choreoathetosis, seizures, aggressive sparring, whole body tremors and prostration at dose levels of 20 to $160 \mathrm{mg} / \mathrm{kg}$ bw. However, as observed in pilot study, the single oral dose of Fenpropathrin did not show any toxic effect at the 5 and $10 \mathrm{mg} / \mathrm{kg}$ bw dose levels. Hence, $10 \mathrm{mg} /$ $\mathrm{kg}$ bw may be considered as NOAEL dose. The outcomes of this analysis show that Fenpropathrin'soral $\mathrm{LD}_{50}$ was found to be $52.72 \pm 8.61$ in male Wistar rats and $48.08 \pm 8.13 \mathrm{mg} / \mathrm{kg}$ bw in female Wistar rats.

Earlier studies with Fenpropathrin demonstrated that the vehicle and the sex of test animal could affect $\mathrm{LD}_{50}$ value.The oral $\mathrm{LD}_{50}$ of Fenpropathrin was reported to be $77.4 \mathrm{mg} / \mathrm{kg}$ bw(corn oil as vehicle) and $164 \mathrm{mg} / \mathrm{kg}$ bw (gum arabic as vehicle) in male Sprague-Dawley rats, where as in female Sprague-Dawley rats the reported oral $\mathrm{LD}_{50}$ was $66.7 \mathrm{mg} / \mathrm{kg}$ bw and $104 \mathrm{mg} / \mathrm{kg}$ bw with corn oil and gum arabic respectively ${ }^{28,29}$. Kohda $(1979)^{30}$ found dermal $\mathrm{LD}_{50}$ of Fenpropathrin (with corn oil as vehicle) to be $1600 \mathrm{mg} /$ $\mathrm{kg}$ bw and $870 \mathrm{mg} / \mathrm{kg}$ bw for male and female SpragueDawley rats respectively. For Japanese albino rabbits, the oral $\mathrm{LD}_{50}$ of Fenpropathrin with corn oil as vehicle was 675 $\mathrm{mg} / \mathrm{kg}$ bw and $510 \mathrm{mg} / \mathrm{kg}$ bw for male and female animals respectively ${ }^{31}$.

In our investigation the oral $\mathrm{LD}_{50}$ of the Fenpropathrin using corn oil as vehicle is $52.72 \pm 8.61 \mathrm{mg} / \mathrm{kg}$ bw in male and $48.08 \pm 8.13 \mathrm{mg} / \mathrm{kg}$ bw in female Wistar rats.

\section{Conclusion}

For forensic toxicologists, the determination of $\mathrm{LD}_{50}$ is very significant for correlating or defining a chemical substance or other poison and for the evaluation ofacute drug toxicity, food poisoning and cases of accidental domestic poisoning. According to standard protocols, Fenpropathrin was investigated, which revealed it to be a highly toxic pyrethroid since its $\mathrm{LD}_{50}$ value is low. It was observed that $\mathrm{LD}_{50}$ value for female rats was lower than that for male rats. The outcome of this study clearly shows that the oral $\mathrm{LD}_{50}$ of Fenpropathrin with corn oil as a vehicle is $52.72 \pm 8.61$ $\mathrm{mg} / \mathrm{kg}$ bw in males and $48.0 \pm 8.13 \mathrm{mg} / \mathrm{kg}$ bw in Wistar rats and NOAEL is $10 \mathrm{mg} / \mathrm{kg}$ bw in both sexes. The result of this study may serve as a basis for dose administration for further research on Fenpropathrin toxicity. 


\section{Conflict of Interest}

None

\section{Acknowledgement}

This work was supported by University Grants Commission.

\section{References}

1. Cao Z, Shafer TJ, Murray TF. Mechanisms of pyrethroid insecticide induced stimulation of calcium influx in neocorticalneurons. Journalof PharmacologyandExperi mental Therapeutics. 2010;336(1):197-205. https://doi. org/10.1124/jpet.110.171850.PMid:20881019.PMCid:P MC3014305

2. Verschoyle RD, Aldridge WN. Structure-activity relationships of some pyrethroids in rats. Archives of Toxicology. 1980; 45:325-9. https://doi.org/10.1007/BF 00293813. PMid:7447703

3. Gammon DW, Brown MA, Casida JE. Two classes of pyrethroid action in the cockroach. Pesticide Biochemistry and Physiology. 1981; 15:181-91. https:// doi.org/10.1016/0048-3575(81)90084-5

4. Lawrence LJ, Casida JE. Pyrethroid toxicology: Mouse intracerebral structure-toxicity relationships. Pesticide Biochemistry and Physiology. 1982; 18:9-14. https:// doi.org/10.1016/0048-3575(82)90082-7

5. Michelangeli P, Robson MJ, East JM, Lee AG. The conformation of pyrethroids bound to lipid bilayers. Biochimica et Biophysica Acta. 1990; 1028:49-57. https://doi.org/10.1016/0005-2736(90)90264-O

6. Weiner ML, Nemec M, Sheets L, Sargent D, Breckenridge C. Comparative functional observational battery study of twelve commercial pyrethroid insecticides in rats following acute oral exposure. Neurotoxicology. 2009. https://doi.org/10.1016/j.neuro.2009.08.014. PMid:197 48519

7. Xiong J, Zhang X, Huang J, Chen C, Chen Z, Liu L, Wang T. Fenpropathrin, a widely used pesticide, causes dopaminergic degeneration. Molecular Neurobiology. 2015. https://doi.org/10.1007/s12035-014-9057-2. PM id:25575680. PMCid:PMC5333774

8. Senin R. Acute toxicity study [Internet]. 2010 Mar 27. Available from: http:/www.ccohs.ca/oshanswers/ chemicasl/Ld50.html.

9. Bliss CI. The method of probits. Science. 1934; 79:38-9. https://doi.org/10.1126/science.79.2037.38. PMid:1781 3446
10. Miller LC, Tainter ML. Estimation of LD50 and its error by means of log-probit graph paper. Proceedings of the Society for Experimental Biology and Medicine. 1944; 57:26. https://doi.org/10.3181/00379727-57-14776

11. Litchfield JT, Wilcoxon F. A simplified method of evaluating dose effect experiments. Journal of Pharmacology and Experimental Therapeutics. 1949; 96:99-113.

12. Thompson WR. Use of moving averages and interpolation to estimate median effective 4 dose. Bacteriol. Rev. 1947; 11:115. https://doi.org/10.1128/ MMBR.11.2.115-145.1947. PMCid:PMC440915

13. Weil CS. Tables for convenient calculation of median effective dose (LD 50 or ED 50) and instructions in their use. Biometrics 1952; 8:249. https://doi.org/10.2 307/3001557

14. Finney DJ. Probit Analysis. 3rd ed. Cambridge: Cambridge University Press; 1971.

15. Randhawa MA. Calculation of LD50 values from the method of Miller and Tainter. 1944. Journal of Ayub Medical College. 2009; 21(3):184-5.

16. Ghosh MN. In statistical analysis, fundamentals of experimental pharmacology, 2nd Ed., Scientific Book Agency Calcutta; 1984:187-9.

17. Horton MK, Jacobson JB, McKelvey W, Holmes D, Fincher F, Quantano A, et al. Characterization of residential pest control products used in inner city communities in New York City. Journal of Exposure Science and Environmental Epidemiology.2011;21:291301. https://doi.org/10.1038/jes.2010.18. PMid:205519 95. PMCid:PMC3377445

18. Ahmed L, Khan A, Khan MZ. Pyrethroid-induced reproductive toxico-pathology in non-target species. Pakistan Veterinary Journal. 2012; 32(1):1-9.

19. Fortes C, Mastroeni S, Pilla MA, Antonelli G, Lunghini L, Aprea C. The relation between dietary habits and urinary levels of 3-phenoxybenzoic acid, a pyrethroid metabolite. Food and Chemical Toxicology. 2013; 52:91-6. https://doi.org/10.1016/j.fct.2012.10.035. PM id:23146693

20. Sinha C, Seth K, Islam F, Chaturvedi RK, Shukla S, Mathur $\mathrm{N}$, et al. Behavioral and neurochemical effects induced by Pyrethroid based mosquito repellent exposure in rat offsprings during prenatal and early postnatal period. Neurotoxicology and Teratology. 2006; 28:472-81. https:// doi.org/10.1016/j.ntt.2006.03.005. PMid:16842967

21. Scollon EJ, Starr JM, Crofton KM, Wolansky MJ, DeVito MJ, Hughes MF. Correlation of tissue concentrations of the pyrethroid bifenthrin with neurotoxicity in the rat. 
Toxicology 2011; 290(1):1-6. https://doi.org/10.1016/j. tox.2011.08.002. PMid:21854826. PMCid:PMC4682199

22. Ansari RW, Shukla RK, Yadav RS, Seth K, Pant AB, Singh D, et al. Cholinergic dysfunctions and enhanced oxidative stress in the neurobehavioural toxicity of lambda-cyhalothrin in developing rats. Neurotoxicity Research. 2012; 22(4):292-309. https://doi.org/10.1007/ s12640-012-9313-z. PMid:22327935

23. Zhang $\mathrm{Y}$, Zhao $\mathrm{M}$, Jin $\mathrm{M}$, Xu $\mathrm{C}$, Wang $\mathrm{C}$, Liu $\mathrm{W}$. Immunotoxicity of pyrethroid metabolites in an in vitro model. Environmental Toxicology and Chemistry. 2010; 29(11):2505-10. https://doi.org/10.1002/etc.298. PMid:20853454

24. Saillenfait A-M. Evaluation of the effects of a-cypermethrin on fetal rat testicular steroidogenesis. Reproductive Toxicology. 2017; 72:106-14. https://doi. org/10.1016/j.reprotox.2017.06.133. PMid:28655647

25. Lazarini CA, Florio JC, Lemonica IP, Bernardi MM. Effects of prenatal exposure to deltamethrin on forced swimming behavior, motor activity, and striatal dopamine levels in male and female rats. Neurotoxicology and Teratology. 2001; 23:665-73. https://doi.org/10.1016/S0892-0362(01)00170-2

26. Soni I, Syed F, Bhatnagar P, Mathur R. Perinatal toxicity of cyfluthrin in mice: developmental and behavioral effects. Human and Experimental Toxicology 2011; 30(8):1096-105. https://doi.org/10.1 177/0960327110391386. PMid:21148197
27. OECD/OCDE 425: OECD guideline for testing of chemicals. acute oral toxicity- up-and-down procedure; 2001. https://doi.org/10.1787/9789264071049-en

28. Hiromori T, Misaki Y, Seki T, Hosokawa S, Miyamoto J. Acute oral toxicity of S-3206 in rats. Unpublished report dated 24 September 1982 from Laboratory of Biochemistry and Toxicology, Sumitomo Chemical Co., Ltd, Japan. Submitted to WHO by Sumitomo Chemical Co., Ltd. (Report No. FT-0076); 1982.

29. Hiromori T, Misaki Y, Seki T, Hosokawa S, Miyamoto J. Acute oral toxicity of S-3206 (97.3\%) in rats. Unpublished report dated 17 January 1983 from Laboratory of Biochemistry and Toxicology, Sumitomo Chemical Co., Ltd, Japan. Submitted to WHO by Sumitomo Chemical Co., Ltd. (Report No. FT0082); 1983.

30. Kohda H. Acute dermal toxicity of S-3206 in rats. Unpublished report dated January 1979 from Institute for Biological Sciences, Japan. Submitted to WHO by Sumitomo Chemical Co., Ltd. (Report No. FT-0019); 1979.

31. Hara S, Suzuki T. Acute oral toxicity of S-3206 in rabbits. Unpublished report dated 12 September 1980 from Research Department, Pesticides Division, Sumitomo Chemical Co., Ltd, Japan. Submitted to WHO by Sumitomo Chemical Co., Ltd (Report No. FT-0039); 1980. 